\title{
Teacher Development, Teacher Beliefs and Professional Development: The Value of Classroom Observations
}

\author{
Vuyisile Msila \\ PO Box 392, College of Education, University of South Africa, UNISA, 0003, South Africa \\ msilavt@unisa.ac.za
}

\author{
Doi:10.5901/mjss.2014.v5n8p265
}

\begin{abstract}
All schools need teachers who are lifelong learners, teachers who engage in on-going professional development throughout their careers. Conscientious school managers will support the professional development of their teachers on a continuous basis. There are no schools that would be able to ensure maximum performance of the learners without teacher diligence, commitment and professionalism. This study reports on the findings of an investigation where three instructional leaders worked with teachers in their schools employing classroom observations. The researcher sought to explore teacher perceptions about classroom observations. It was clear from this study that teachers who are aware of their need to change their beliefs will benefit from classroom observations. The participants agreed that classroom observation has elements which enhance teacher growth and these are mentoring and coaching aspect; making teachers critical thinkers and meaningful feedback. The participants also discovered that through effective classroom observations teachers will change their belief system for the better.
\end{abstract}

Keywords: Teacher effectiveness. Professional development. Critical teaching. Learner achievement.

\section{Introduction and Background}

Teacher development is crucial for all schools that seek to ensure learner success and foster the culture of lifelong learning among teachers. Lifelong learners need to be evaluated from time to time. Yurekli (2013) points out that observations are a key aspect of evaluation as they are the most used means of recording teacher performance during class. Teacher appraisal will be incomplete without classroom observation. Yurekli (2013) also postulates that there are four main reasons for class observations namely: to provide help for novice teachers; to monitor teacher performance in terms of staff development; to offer help to those who experience problems; and to identify staff needs. Lakshmi (2013) writes about the need of peer observation and refers to this as the process where colleagues observe others in their teaching with an objective of improving teaching practice. Classroom observations should deal with what Cerbin (2013) refers to as the learning question. Cerbin describes the learning question as first about outcomes-what or how much did the students learn. He contends:

It is typified by these kinds of research questions: Did the new teaching methods I used produce better learning than the traditional method I have been using; Did the new assignment I used result in better student performance than the one I typically use; Did the strategy our department adopted have a positive effect on student performance in the capstone course; Did our institutional emphasis on critical thinking lead to better thinking among students across disciplines?

Anyone who observes any classroom will look for this learning question with a view to assist the teacher. Effective teachers conduct lessons in classrooms because they want their pupils to learn.

Effective classroom observations should have an effect on teacher beliefs. Uztosun (2013) affirms that it is crucial to have an effect on teacher beliefs because these are the basis of action and when one understands teacher beliefs one will understand their professional world. People who observe teachers in classrooms will see the teachers' beliefs and they will only change the teachers' practice if they as observers, appeal to the teachers' beliefs. Appealing to teacher beliefs in a certain way will ensure that we groom teachers who are passionate about teaching and dedicated to the performance of their pupils. Mart (2013) contends that passion motivates and inspires teachers. It is an element that affects teacher performance. Furthermore, Mart avers that passionate teachers know that it is their duty to encourage pupils for active learning. With the right belief system all teachers will be passionate. Effective mentors will support teachers to develop into passionate classroom practitioners. The continuing professional development of teachers 
provides an important tactic for improving schools and increasing teacher quality (De Vries et al. 2013). Classroom observation is an aspect of continuing professional development not only for novice teachers but for all practising teachers.

This study explored the views of teachers towards classroom observation. It sought to understand how they understood their roles as well as the roles of instructional leaders who led the classroom observations. The main questions asked were:

How do teachers perceive the role of classroom observations of their own practice?

How do they reconcile the evaluators' comments and their beliefs?

\title{
2. Objectives of the Study
}

This study was guided by a few objectives. The study wanted to:

- Explore how the role of classroom observations can effect teacher change;

- Investigate the best practices for classroom observation;

- Discover how one can engage with evaluator's comments as they enrich their practice; and

- Explore how classroom observations can really support on-going professional development.

\section{Literature Review}

Professional development is synonymous with lifelong learning. As teachers we need to continue learning throughout life especially in an age when a pupil is expected to share learning and teaching in the classroom. The post-apartheid system of education envisages a new kind of a teacher who is critical and engaging lifelong learner. Schools today need high quality professional development.

Guskey (2002:383) argues:

\begin{abstract}
Professional development activities frequently are designed to initiate change in teachers' attitudes, beliefs, and perceptions. Professional development leaders, for example often attempt for change teachers' beliefs about certain aspects of teaching or the desirability of a particular curriculum or instructional innovation. They presume that such changes in teachers' attitudes and beliefs will lead to specific changes in their classroom behaviours and practices, which in turn will result in improved student learning.
\end{abstract}

Effective classroom observation is meant to achieve activities that would result to the above. The evaluator in classroom observation seeks to see professional development that would result to pupil success. It is not only one classroom observation that would change teachers. Harvell (2003) proclaims that teacher professional development is not an event but a process. It needs time as well as an agreeable environment. Without a conducive environment professional development will not succeed.

Changes cannot and will never be effective without conscientious teachers. Teachers owe this to their pupils and their countries. Effective professional development makes teachers to pay their attention to what really happens in classrooms. Mohammadi et al. (2013) point out that educators should respond to the following questions: What should be learned? How to learn? Why to learn? These authors state that educators should put more emphasis on self-judgement and self-controlling issues. The latter is the basis of teaching children to be critical thinkers. Teachers must be aware of their professional growth as thinkers otherwise they will not be able to nurture thinkers. Mohammadi et al. (2013:654-655) postulate, "teachers need to rethink about their role again focusing on their own activities on training skills because this leads to nurture students' critical thinking way". Critical thinking in classrooms depends on teacher readiness and professional accomplishment. A teacher needs to have attained best practices.

Pascarella and Blaich (2012) mention effective instruction as key to problem solving among learners. Effective instruction will be practiced by effective teachers who will foster intellectual skills and orientations. Abu-Dabat (2013) states that in education there need to be the training skill that develops the capacity of individuals and contribute to solving the problems they face thus leading to the progress of the nation. Effective, well-prepared teachers will be good for this purpose. As highlighted above, the quality of education is largely determined by the quality of the educators. Ahmad et al. (2013) point out that reflectivity increases the abilities of the teachers to plan, organise, critically think, observe and create. "It enables teachers to learn new and variety strategies of teaching and learning in the process of education" (Ahmad et al. 2013:73). Ahmad et al. (2013) write about a need for teachers to develop over their career span. These authors also identify six phases of the teachers' reflective growth namely, novice, apprentice, professional, 
expert, distinguished and evaluative. It may be necessary to ensure that teacher moves through these phases to attain their roles as reflective practitioners who employ critical thinking skills. These teachers grow and tend to perceive teaching as a critical process. Other authors emphasise that for teacher growth to flourish there needs to be both reflection as well as reflexivity. Below, the focus is on the research methodology employed in this study.

\section{Research Methodology}

This study was a qualitative study where three principals who visited teachers in their classrooms and 15 teachers were observed and interviewed. Purposeful sampling was used in selecting the participating schools and school managers. According to Struwig and Stead (2004) purposeful sampling is more concerned with the provision of a sample of information-rich participants. The participants need to show certain characteristics that the researcher is interested in. The researcher visited the three schools and this is where the observations and interviews took place. All the 15 participants were interviewed individually during the course of the study which spanned over three months. In these three schools the school managers were already supportive of classroom visits which were conducted on a continuous basis throughout the year. The researcher attended the classroom observations of all the 15 teachers to observe what really happens during teaching time. During the observations the researcher was a non-participant observer. During the observations the researcher wrote notes as he followed what was happening. The observation schedule included the following:

- Lesson plan;

- Learner participation;

- The classroom observer role (school manager/observer/peer coach);

- The post-class conference between the teacher and the school manager/classroom observer;

After each individual interview the researcher gave the interviewees the transcripts to verify the information. All the interviews were conducted in English which is a second language of all the participants but a language used daily in the schools. Not all the participants agreed to be audio-taped during the interview sessions. For ethical reasons the researcher was only able to record nine of the fifteen participants. These nine participants consented in being audiotaped. The participants were also assured that their schools and their names will not be recognisable in the actual research report.

\section{The Discussion of the Findings}

\subsection{Feedback and Observation}

The participants all agreed that feedback after each observation was fundamental in professional development. They pointed out that this is what built their maturity after each observation. The school managers who were observers also stated that they learn a lot about themselves during the process of exchanging ideas with the observees. One observer postulated that he spotted a number of possibilities during the classroom observations and saw possibilities of novel approaches as well. The classroom observation process enabled the observees to be able to do their own introspection of their teaching as well. One stated that classroom observation develops the professional acumen of both the observer and the observed. Feedback helps the teachers to talk about the experiences. In the study though, teachers concurred that they rarely get feedback any day at work. Ho and Kane (2013) highlights that for many teachers classroom observation has been the only opportunity to receive direct feedback from another school professional. Among the participants who were observed, there was a video recorder used by one school manager (observer). The observees found it even more fulfilling having to sit down and relook at the lesson critically. The video enhanced the coaching and mentoring aspects of classroom observations. The feedback sessions generally enrich the observed teachers with these. Hora and Ferrari (2013) also point out that peer observers will not simply conduct a single observation but will integrate pre-and post-class interviews or coaching sessions and provide the teachers with targeted feedback. These are all crucial for professional development.

The participants stated that if teachers got feedback about their teaching throughout their career teaching would be fulfilling for both the teachers and their pupils. However, the participants stated that teachers are usually scared of criticism hence they will tend to isolate themselves. Teachers need this feedback although it is not without problems. Yurekli (2013:2) avers: 
observee and the observer, as it is almost impossible to remain purely objective and non-judgemental at every stage of the feedback (William 1989). 'Feedback' as the concept is commonly understood requires a certain degree of 'view', perspective, 'value' and 'stance' on a given experience or issue. As such feedback implies an intervention based on some conception formed earlier by the observer on what s/he sees as a good teacher or lesson.

Both the observers and the observees in the study maintained that they experienced nervousness after each of the classes. Yet feedback needs to follow professionalism, respect and trust. Teachers observed expect to grow from each classroom observation. The observation feedback should be able to offer this. As highlighted above, teachers also need to observe and be observed throughout their teaching lives if professional development is to be meaningful. There is never a professional who cannot learn anything and observations and feedback have to be understood within this context. Another crucial aspect in this study was mentoring and coaching as a function of classroom observations.

\title{
5.2 Mentoring and Coaching in Classroom Observations
}

Hudson (2013) points out that schools can provide a vehicle for connecting theory with practice and mentor teachers are pivotal to teacher development. Most studies show that mentors are crucial to beginning teachers because mentoring is part of early career induction (Cowin 2013). In this study though, we see that classroom observation of 'experienced teachers' make the mentoring of all teachers necessary. This study showed that for professional development, all teachers need continued support and mentoring. Lofthouse and Wright (2012) point out that activity of classroom observation and feedback by school mentors are activities where several learning activities take place, at times from differing perspectives of the observer and the observed. Lofthouse and Wright (2013:89) state that mentors and teachers are "engaged in developing their professional identity, shaped by sometimes differing practical expectations, academic demands and cultural values of both university and school". These authors refer to the dialogue between the observer and the observee as a boundary crossing which can be a source of tension but are also a potential for learning.

Classroom observation in this study showed qualities of both peer coaching as well as mentoring. Both are important aspects of professional development. Zepeda, Prylo and Iglan (2013) state that effective coaching is a continuous process built on clear goals and trust. Zepida et al. (2013:65) contend:

\begin{abstract}
Peer coaching can be described as a system of reciprocal learning and support. In the peer coaching process, support is delivered in safe environment "for the purpose of improving instructional skills"....Peer coaching provides the coaching pair with a very practical and powerful way of learning about their own and each other's teaching" (p.113). Peer mentoring is similar but in peer coaching, both participants are equal while in peer mentoring, the mentor is generally regarded as more experienced one in the dyad (Leidenfrost et al., 2011).
\end{abstract}

Both of these were prominent in this study. The observers saw their roles as both mentors and peer coaches. In the visits there were the informal aspects of peer coaching as well as formal aspects of peer mentoring. It was the combination of these two that made the participants grow. In fact, teachers appeared to prefer the freer non-threatening aspects of peer coaching. During the one on one discussion after classroom observations, the observers talked at length about the necessary skills in the classrooms. Chien (2013) also points out that coaches help provide teachers with quality professional development experience by mentoring, modelling and encouraging professional growth. Two of the observers were always helping the observees in lesson planning before class. This is one of the functions that Chien refers to as a crucial function of the coaches. Furthermore, Chien cites Bean (2004) who identifies three levels of activities associated with coaches. Level one includes informal activities such as curriculum development. Level two activities are focused on area needs such as co-planning of lessons as well as co-teaching. Level three refers to visiting classrooms and providing teachers with feedback. In effecting all this support, the mentors and coaches are engaged in an endeavour to create critical thinkers from the teachers.

\subsection{Critical Teacher Reflection}

Many mentors who think deeply about professional development would couple classroom observations with journal writing. Yet classroom observation is part of teacher reflection. The participants in the study concurred that going into class then later contemplate and talk about their classroom experiences made them understand their practice more. In fact, they concurred that since starting classroom observation sessions and teacher reflection they had also started talking openly about their practice among their peers. Teacher reflection had also broken the isolation that existed before because teachers were sharing what they experienced in the classrooms. This was even more beneficial to novice 
teachers and those who were under-qualified. The teachers also expressed that teacher reflection made them "understand the psychology in teaching and learning". Teacher reflection supports the idea of lifelong learning or teacheras-learner concept. Choy and Oo (2012: 169) point out:

Teacher reflection can be thought of as taking the necessary steps to analyse and articulate problems before taking action. This allows for more constructive action to be taken rather than implementing a quick fix (Boody 2008). The challenge is to be able to demonstrate in action what is taught in the classroom. Many teachers fail to connect between their teaching and what they are actually practicing and vice versa.

According to the school managers who were observers during teaching, teacher reflection was not empowering teachers only but was also instrumental in empowering the learners. The teachers stated that they had learnt to be more responsive to specific learner problems and their pedagogy started to suit the needs of the learners. One principal also saw this "as a good strategy in dealing effectively with curricular challenges". He said that in his conversation with many of his staff during class visits, he has seen them grow and being able to ask the pertinent questions. As an instructional leader he maintained that the critical reflection "made his job as a curriculum leader much easier".

The observees emphasised that several factors were positively affected by the classroom visits and these included:

- Understanding their practice;

- Understanding colleagues;

- Learning to be critical;

- Getting to know their beliefs; and

- $\quad$ Finding ways to put the pupils first.

These were factors shared by all the participants both observers and observees. Classroom observations make everyone to be learners. The observers cannot be effective classroom observers if they have not accepted the role of learners. In order to help others teach better one needs to learn from the observed as well.

\section{Conclusion}

In conclusion, it is clear that there are many positive aspects that can be benefited from properly conducted classroom observations. When diligent teachers are shown the need for classroom observations, they will use it to improve their learning and professionalism. Like all workers, teachers would like their space to be respected therefore observers should approach the teachers' space (the classrooms) with respect and sensitivity. The teachers in the study saw the need of observations and all gained from the process. They acknowledged the role of classroom observations as part of their professional development. Even those who were sceptical and did not feel comfortable at having somebody else in their classrooms, they understood the basic need of the observations. Even those who initially regarded the classroom observations as invasion earlier later understood the objectives of classroom observations and their long term goals including opportunities for professional development. The observers also used the evaluators' comments and discussions as a way of introspection. They were able to use these to confront their beliefs, reflecting on their teaching and trying to work hard for pupil success. The participants concurred that classroom observations lay a good foundation for critical reflection and improving teacher practice. It was also interesting to hear teachers state that classroom observations should not be reserved only for novice teachers but should be utilised for "experienced" teachers as well. Judging from the perceptions of the participants, classroom observations should be continuous throughout the teacher's life. Below, the focus is on the recommendations drawn after the study.

\section{Recommendations}

The utilisation of classroom observations in this study enabled the researcher to draw the following three recommendations:

Firstly, the study concluded that all teachers should continuously be visited in their classrooms whilst teaching. This does not only help in the development of individual teachers but also helps in breaking teacher isolation that normally detaches teachers from their colleagues. Classroom observations make the classroom walls to be more permeable especially when the observees will share the experiences of the observations with other teachers in a positive manner with intent to improve teacher practice.

Secondly, all school managers should learn the skill of observing teachers in their classrooms. Effective schools 
can only be created if the management knows what is happening in classrooms. In many schools teachers do as they wish in classrooms and are never observed for improvement. This is the basis of many problems and the burgeoning numbers of failing schools. The district officials should train school managers to know exactly what to do during classroom observations. When the school managers are empowered in teacher evaluation, they are likely to produce effective schools.

Thirdly, schools need to instil a culture of peer observation where colleagues should be able to assess one another's teaching. This is a huge responsibility of the school management who should ensure that the conditions are conducive for teacher observations. Trust, professionalism and rapport should all be developed for teachers to appraise one another honestly. Teachers who know what needs to be observed during classroom observations will themselves build their teaching skills.

Finally, more research needs to be conducted on the subject of classroom, observation. If we are to prepare winning schools with successful pupils we will need to underscore the role of classroom observations. The concept of teachers as researchers is also not widespread in countries like South Africa. Teachers should be supported in conducting action research where they investigate their own practice.

\section{References}

Abu-Dabat, Z. 2013. The Achievement and Development of Critical Thinking Skills in the Arabic Language of Adolescent Pupils With reference to The Primary Stage throughout Jordan. International Journal of Humanities and Social Science, 3(5), 155-162.

Ahmad, I., Said, H.B., Zeb, A., Rehman, S., Ahmad, S., \& Khan, W. 2013. How reflective practice improves teachers' classroom teaching skill? A case of community based schools in district Chitral, Khyber Pakhtunkhwa. Social Sciences and Humanities, 4(1), 73-81.

Amalia, L.L., \& Imperiani, E.D.A. 2013. Mentor Coaching to help Pre-service Teachers in designing an Effective Lesson Plan. Indonesian Journal of Applied Linguistics, 2 (2), 275-280.

Cerbin, B. 2013. Emphasising learning in the scholarship of teaching and learning. International Journal for the Scholarship of Teaching and Learning and Learning, 7(1), 1- 6.

Chien, C. 2013. Analysis of an Instructional coach's role as elementary school language teachers' professional developer. Current Issues in Education, 16(1), 1-12.

Choy, S.C., \& Oo, P.S. 2012. Reflective thinking and teaching practices: a precursor for incorporating critical thinking into the classroom? International Journal of Instruction, 5(1), 167-182.

Claris, L. 2013. "To know is not enough": critical thinking in a Krishnamurti school. Journal of the Krishnamurti schools, 17, 116-123.

Cowin, K.M. 2013. A Call to Action: What Student Teachers can teach us. Northwest Journal of Teacher Education, 11(1), 1-30.

De Vries, S., De Grift, W.J.C., \& Jansen, E. 2013. Teachers' beliefs and continuing professional development. Journal of Educational Administration, 51 (2), 213-231.

Farrell, T. 2011. 'Keeping SCORE': Reflective Practice through Classroom Observations. RELC Journal, 42 (3), 265-272.

Guskey, T.R. 2002. Professional development and teacher change. Teachers and Teaching: Theory and Practice, 8(3/4), 381-391.

Harvell, S.H. 2003. Teacher Professional Development: It's not an event, it's a process. CORD, 1-12.

Ho, A.D., \& Kane, T.J. 2013. The reliability of classroom observations by school personnel. Boston: MET.

Hora, M.T., \& Ferrare, J.J. 2013. A Review of Classroom Observation Techniques in Post-secondary Settings. WCER WORKING PAPER 2013. [Online] Available: From<http://www.wcer.wisc.edu/publications/workingPapers/paprs.php. May 21, 2013.

Hudson, P. 2013. Mentoring pre-service teachers on school students" differentiated learning. International Journal of Evidence based Coaching and Mentoring, 11(1), 112-118.

Lakshni, B.S. 2013. Seeing is believing: Use of peer observation for professional development. Indian Journal of Applied Research, 3(5), 381- 382 .

Lofthouse, R., \& Wright, D. 2012. Teacher Education Lesson Observation as Boundary Crossing. International Journal of Mentoring and Coaching in Education, 1(2), 89-103.

Mart, C.T. 2013. A passionate teacher: teacher commitment and dedication to student learning. International Journal of Academic Research in Progressive Education and Development, 2(1), 437- 442.

Mohammadi, R., Naderi, E., Shariyatmadari, A., \& Naraghi, M.S. 2013. The study of the effect of centralised planning system on the development of critical thinking in elementary school students. European Journal of Experimental Biology, 3(1), 654-660.

Pascarella, E.T., \& Blaich, C. 2012. Lessons from the Wabash National Study of Liberal Arts Education. Change.-The Magazine of Higher Learning, 45(2), 6-15.

Struwig, F.W., \& Stead, G.B. 2004. Planning, designing and reporting research. Cape Town: Pearson Education.

Uztosun, M.S. 2013. An interpretive study into elementary School English Teachers' Beliefs and Practices in Turkey. Turkish Online Journal of Qualitative Inquiry, 4(1), 20-33.

Yurekli, A. 2013. The six-category intervention analysis: A classroom observation reference. ELT Journal, 67 (1), 1-11.

Zepeda, S.J., Parylo., O., \& Ilgan, A. 2013. Teacher peer coaching in American and Turkish Schools. International Journal of Mentoring and Coaching in Education, 2 (1), 64-82. 